\title{
SISTEMA MUNDO MODERNO, COLONIALIDAD Y ESTADOS NACIONALES EN AMÉRICA LATINA: EL LUGAR DEL “OTRO”
}

Tania Rodriguez, Ravera ${ }^{1}$

\begin{abstract}
Resumen: En este artículo discutimos y analizamos los procesos desencadenados por la colonización de América y cuál fue el papel de nuestro continente en el surgimiento del Sistema Mundo Moderno y de la economía capitalista mundial. También buscamos identificar y analizar el lugar que ocuparon los sectores populares en esos procesos, que asentarían las bases de la colonialidad aún vigente, dentro de las dinámicas de construcción de un "Otro" por parte de las élites hegemónicas. Para ello, nuestro enfoque estará direccionado hacia algunos aspectos y elementos de la estructura económica latinoamericana y los acontecimientos ocurridos a nivel internacional, fundamentalmente en la segunda mitad del siglo XIX, como la inserción de los nacientes estados nacionales en la división internacional del trabajo.
\end{abstract}

Palabras claves: sectores populares; economía política; estados nacionales.

\begin{abstract}
In this article we discuss and analyze the processes unleashed by the colonization of America and what was the role of our continent in the emergence of the Modern World System and the world capitalist economy. We also sought to identify and analyze the place occupied by the popular sectors in these processes, which would establish the basis of coloniality still in force, within the dynamics of building an "Other" by the hegemonic elites. To this end, our focus will be on some aspects and elements of the Latin American economic structure and the events that occurred at the international level, mainly in the second half of the XIX century, such as the insertion of the nascent national states into the international division of labor.
\end{abstract}

Key-words: popular sectors; political economy; National States.

\section{INTRODUCCIÓN}

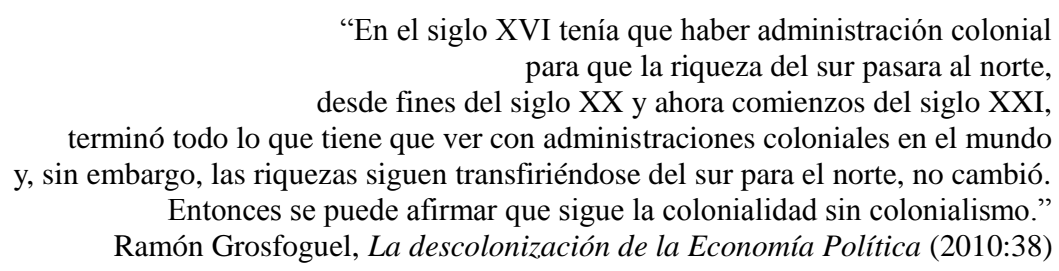

Actualmente, especialmente en los países del Cono sur, vivimos señales de una nueva onda conservadora en el continente, que retoma la pauta neoliberal con mayor vigor atacando directamente los derechos conquistados en luchas históricas por los sectores populares. Algunos ejemplos claros son la actual presidencia brasileña de Michel Temer (asumida en medio de una gran crisis política que llevó al impechmeant de la presidenta electa Dilma Rousseff), y el presidente argentino Mauricio Macri. En el primer caso, el gobierno interino está promoviendo varias reformas a las legislaciones que regulan la providencia social y leyes de protección de derechos de trabajadores, así como cerró varios Ministerios, como el de la

\footnotetext{
${ }^{1}$ Programa de Posgrado en Integración Contemporánea de América Latina - PPG/ICAL, de la Universidad Federal de la Integración Latinoamericana (UNILA), situada en Foz de Iguazú-PR, Brasil.
} 
Cultura y el de Mujeres, Igualdad Racial y Derechos Humanos, aumentó el recorte de gastos públicos, entre otras medidas2.

Por su parte, dentro del basto programa neoliberal que Macri implantó en pocos meses de gobierno, resaltamos las reformas de la providencia social, gran ola de despidos desde instituciones estatales de la cultura como el Instituto Nacional de Cine y Artes Visuales INCAA, funcionarios de la Aduana, como trabajadores de la construcción e industria (se contabilizan más de 154 mil desocupados en lo que va de gobierno), incremento de los precios de la gasolina, el gas, el agua, la electricidad y el transporte que contaban con subsidio del gobierno federal3.

En este contexto, de una fuerte retomada de la pauta neoliberal y vulneración de derechos de las camadas populares, al proponernos pensar la integración regional y los desafíos a los que se enfrenta América Latina, se torna necesario analizar el fuerte dilema de la (des)integración social. Pero, comprendiendo que históricamente, desde la conformación de los estados nacionales, ciertos grupos (trabajadores, indígenas, negros, pobres, mujeres) han sido subalternizados y excluidos de las esferas de la "nación" por las élites dominantes (COELHO PRADO, 2008:600), reconocemos que la problemática de la desintegración social nace con los propios estados.

Planteamos esto porque creemos que los problemas actuales de nuestros países no pueden ser vistos con una lupa de corto alcance, sino que debe ampliarse la mirada en retrospectiva, y buscar comprender las raíces de las circunstancias que nos afectan en nuestro presente caminar. En las palabras de Fernand Braudel,

O entendimento útil (digo-o e repito-o insistindo) sobre a longa duração, essa estrada essencial da história, não a única mas que coloca por si só todos os grandes problemas das estruturas sociais, presentes e passadas. É a única linguagem que liga a historia ao presente, convertendo-a em um todo indissolúvel. (BRAUDEL, 2007:8)

En ese sentido, al mirar el presente actual nos cuestionamos acerca del lugar y el papel desarrollado por los sectores subalternos latinoamericanos en la constitución de la Modernidad, en la conformación de la economía-mundo capitalista y en los propios procesos de constitución y consolidación de los estados nacionales en la región. Ya que comprendemos que al indagar y buscar reconstruir ese pasado, podremos delinear algunas de las raíces de la

2 En el próprio discurso de asunción a la presidencia Temer expone algunas de essas medidas que adoptó e irá adoptar en los próximos meses de gobierno. Ver discurso: http://noticias.uol.com.br/politica/ultimasnoticias/2016/05/12/michel-temer-discursa-apos-assumir-presidencia.htm

3 Ver http://www.telesurtv.net/news/Macri-intenta-atenuar-crisis-economica-con-nuevas-medidas20160416-0027.html; http://www.eltiempo.com/mundo/latinoamerica/gobierno-de-mauricio-macri-encrisis-economica/16593104; http://www.telesurtv.net/news/Gobierno-de-Macri-lleva-154-mil-786despidos-en-Argentina-20160518-0002.html . Accesos: 25/06/2016. 
estructura de dominación-exploración existente en América Latina y del capitalismo dependiente que nos caracteriza. Que en momentos de crisis, como la actual, las élites dominantes buscan garantizar su poder y su lucro a través de la mayor explotación de los trabajadores, y de la vulneración de derechos humanos mínimos conseguidos por las clases populares a lo largo de la historia.

Así es que en este trabajo, en un primer momento, nos proponemos problematizar y analizar los procesos desarrollados desde la colonización de América y cuál fue el papel de nuestro continente en el surgimiento del Sistema Mundo Moderno y de la economía capitalista mundial. A su vez, intentaremos aproximarnos al análisis del lugar que ocuparon los sectores populares en esos procesos, que asentarían las bases de la colonialidad aún vigente. En el segundo apartado nos enfocaremos en algunos aspectos y elementos de la estructura económica latinoamericana y los acontecimientos ocurridos a nivel internacional, fundamentalmente en la segunda mitad del siglo XIX, como la inserción de los nacientes estados nacionales en la división internacional del trabajo. También buscaremos analizar algunos reflejos de esos procesos dentro de los propios estados en fase de consolidación y cuál fue el lugar de las camadas populares en esos fenómenos. Para finalizar realizaremos algunas consideraciones finales.

\section{SISTEMA MUNDO MODERNO, COLONIALIDAD Y AMÉRICA LATINA}

Immanuel Wallerstein en su libro O sistema mundial moderno (1990), propone que el único sistema social existente es el sistema mundial, por lo que al proponerse estudiar la creación del mundo moderno y las transformaciones ocurridas a lo largo del tiempo en el sistema mundial de la Edad Moderna, percibió que no podía adoptar como unidad de análisis únicamente los Estados Nacionales o Sociedades nacionales (1990:18). En su obra, el autor define que a partir del siglo XV y XVI (1450-1640) se dan los orígenes y condiciones iniciales del sistema mundial. Éste, a su vez, se consolidará entre 1640 y 1815, para convertirse realmente en un economía-mundo global en el período de 1815 a 1917. Según él, esta tercera - pero no última - fase, fue posible por la transformación tecnológica del industrialismo moderno (1990:22).

Es importante recordar que durante los siglos XIV y XV, la economía y las sociedades europeas se encontraban en una profunda crisis, marcando notoriamente las limitaciones del sistema feudal en lo que sería el último período de la Edad Media. "La institución del trabajo servil, como mecanismo de extracción de excedente, basaba la explotación económica y la 
coerción político-legal, en el nivel molecular de la aldea" (ANDERSON, 2004:19). Esa "unidad" de opresión política y económica de los campesinos fue debilitada y amenzada de separarse, con el desaparecimiento gradual de la servidumbre. Uno de los finales de ese proceso fue el comienzo del "trabajo libre" en los países europeos, principalmente en Inglaterra, quien desarrolló más rápida y fuertemente las bases productivas industriales capitalistas. Wallerstein plantea que

Foi no século XVI que se constituiu uma economia-mundo europeia baseada no modo de produção capitalista. [...] A característica distinitva de uma economíamundo capitalista é a de que as decisões económicas estão orientadas primariamente para a arena da economia-mundo, enquanto as decisões políticas estão primariamente orientadas para as estructuras mais pequenas que têm controle legal, os estados (nações-estados, cidades-estados, impérios) dentro da economia-mundo. [...] O sistema de classes moderno começou a tomar forma no século XVI. [...] No entanto, para a economia-mundo europeia como um todo, consideramos 1450-1640 como a unidade temporal significativa durante a qual foi criada uma economíamundo capitalista, uma economia-mundo que era com certeza, na frase de Braudel, <<vasta mas fraca〉>. (WALLERSTEIN, 1974:73-74)

En ese nuevo régimen emergió una división del trabajo tanto entre los sectores de producción (agrícolas, industriales, comerciales) como dentro de las propias tareas relacionadas a la agricultura, ya que con la incorporación de América al sistema colonial europeo, y a la conformación del sistema mundo moderno, fue expandida la producción agrícola a estas tierras, por ejemplo, en la explotación de la caña de azúcar. Para Wallerstein, la expansión europea implicó un desarrollo desigual estratificado, de camadas dentro de camadas, cada una de las cuales polarizada en términos de una distribución bimodal de recompensas (1990:91).

Assim, concretamente, no século XVI, havia o diferencial do centro da economiamundo europeia versus as suas áreas periféricas, dentro do centro europeu havia-o entre estados, dentro dos estados entre regiões e estratos sociais, [...] (WALLERSTEIN, 1990:91).

El sistema mundo moderno nació basado en un sistema complejo de distribución de las tareas productivas, que conlleva diferentes modos de organización y control del trabajo. Por ejemplo, mientras en Europa - centro de la economía-mundo - se expandía el trabajo asalariado, en América - periferia de la economía-mundo- se utilizó hasta el siglo XIX, fundamentalmente, fuerza de trabajo esclava. Mientras que en zonas de la semi-periferia se desarrollaron formas de parceria.

Si bien los procesos de producción estaban integrados dentro de la división del trabajo establecida en la economía mundo, las periferias serían las zonas que perdieron en la distribución de la plusvalia para las zonas del centro económico. Los criterios que Wallerstein 
utiliza para establecer esas tres categorías dentro de la economía mundo son la acumulación de capital, la organización social de los procesos de producción locales y la organización políticas de las estructuras estatales en creación (FRIGGERI; CARVALHO, 2013:124). En ese sentido,

De acuerdo con Wallerstein (1999), es prácticamente imposible el desarrollo de Latinoamérica, ya que lo que se desarrollan no son países o regiones aisladamente, sino la economía-mundo capitalista. Esa economía-mundo se encuentra basada en una estructura orgánica compuesta de una región central, una semi-periférica y otra periférica, y, a pesar de haber sido ratificada después del siglo XIX, tiene sus fundamentos en el siglo XVI. (FRIGGERI; CARVALHO, 2013:124)

A partir de lo expuesto anteriormente, reconocemos que la "conquista" y colonización de América se constituyó como uno de los acontecimientos más importantes para el surgimiento y desarrollo de la Modernidad, así como del propio sistema capitalista aún vigente. Pero se hace necesario destacar que esos procesos fueron en base al saqueo, expropiación y explotación tanto de las riquezas naturales aquí existentes como a través de la utilización de fuerza de trabajo esclava, primero indígena y luego también africana.

é a conquista da América que anuncia e funda nossa identidade presente. Apresar de toda data que permite separar duas épocas ser arbitrária, nenhuma é mais indicada para marcar o início da era moderna do que o ano de 1492, ano em que Colombo atravessa o oceano Atlântico. (TODOROV, 1998:6)

Asi mismo, tal como establece Karl Marx en El Capital (1988), la explotación de mano esclava indigena y africana fueron algunos de los factores fundamentales en la acumulación primitiva necesaria para el surgimiento y desarrollo del sistema capitalista (1988:872). Marx resalta en su análisis el papel desempeñado por la violencia (conquista, esclavitud, rapiña y asesinato) como los métodos principales utilizados para conseguir esa acumulación primitiva (1988:836) tanto em Europa con la expropiación de la tierra a los campesinos (1988:838) como en América a través de la rapiña y la esclavitud indígena (1988:872). El autor también plantea que los "descubrimientos" de finales del siglo XV, así como otros procesos desencadenados durante la Edad Media europea, fornecieron dos formas de capital, el mercantil y usurero, que amudecieron en las diversas formaciones económicosociales y fueron las que emergieron como capital antes de despontar la era capitalista (MARX,1988:871). Según él,

El sistema colonial hizo prosperar el comercio y la navegación. Las sociedades dotadas de monopolio, que ya hablaba Lutero, eran poderosas alavancas de concentración del capital. Las colonias aseguraban mercado a las manufacturas em expansión, y gracias al monopolio, una acumulación acelerada. Las riqeuzas apresadas fuera de Europa por el saqueo, esclavitud y masacre refluian para la metrópolis, donde se transformaban en capital. (MARX, 1988:875) 
Al mismo tiempo, argumenta que el secreto que la economia política del viejo mundo descubrió en el Nuevo fue el modo capitalista de producción y acumulación, y por tanto, la propiedad privada capitalista exige, como condición existencial, el aniquilamiento de la propiedad privada basada em el trabajo próprio, esto es, la expropiación del trabajador (1988:899).

En gran consonancia con los análisis realizados por Marx, Ruy Mauro Marini en su texto A diáletica da dependencia de 1973, plantea que América Latina de desarrolló en estrecha consonancia con la dinámica del capitalismo internacional al ser forjada en el calor de la expansión comercial promovida desde el siglo XVI (MARINI, 2011:133).

Colônia produtora de metais preciosos e gêneros exôticos, a América Latina contribui em um primeiro momento com o aumento de fluxo de mercadorias e a expansão dos meios de pagamento, que, ao mesmo tempo em que permitiam o desenvolvimento do capital comercial e bancário na Europa, sustentaram o sistema manufaturero europeu e propiciaram o caminho para a criação da grande industria. (MARINI, 2011:133-134)

La importancia de América Latina en la conformación del Sistema Mundo Moderno es analizada y reconocida por los autores citados anteriormente. Todos ellos tienen como premisa compartida: el innegable papel de nuestra región para la formación de la economía capitalista mundial. Pautado esto, queremos plantear algunos elementos sobre el proceso de colonización, explotación y dominación implantado en la región desde fines del siglo XV e inicio del XVI.

Alfredo Bosi, en su libro Dialética da Colonização (2013), explica que "la colonización no puede ser tratada como una simple corriente migratoria, ya que ella es la carencia y conflictos de la matriz y una tentativa de retomar, bajo nuevas condiciones, el dominio sobre la naturaleza y el semejante que tiene acompañado universalmente el llamado proceso civilizador” (BOSI, 2013:13). El autor realiza un análisis de la etimología de la palabra ‘colonización’ y sus vinculo con ‘culto’ y ‘cultura'. Allí establece que

As palavras cultura, culto e colonização derivam do mesmo verbo latino colo, cuyo partícipio passado é cultus e o participio futuro é culturus. Colo significó, na língua de Roma, eu moro, eu ocupo a terra, e por extensão, eu trabalho, eu cultivo o campo. Um herdeiro antigo de colo é incola, o habitante; outro é inquilinus, aquele que reside em terra alheia. Qquanto a agricola, já pertence a um segundo plano semântico vinculado à ideia de trabalho. [...] Colo é a matriz de colonia enquanto espaço que se está ocupando, terra ou povo que se pode trabalhar e sujeitar. Nao por acaso, sempre que se quer classificar os tipos de colonizacao, distinguem-se dois processos: o que se atém ao simples povoamento, e o que conduz á exploração do solo. Colos está em ambos: eu moro; eu cultivo. [...] Como se fossem verdadeiros universais das sociedades humanas, a producao dos meios de vida e as relacoes de poder, a esfera economica e a esfera política, reproduzem-se e potenciam-se toda vez que se poe em marcha um ciclo de colonizacao. [...] (BOSI, 2013:11-12) 
En esse sentido, Bosi argumenta que el trazo de la dominación es inerente a las diversas formas de colonización, ya que la colonización es en sí un proyecto totalizante cuyas fuerzas motrices podrán siempre buscarse en el nivel del colo: ocupar un nuevo suelo, explotar sus bienes y someter a sus naturales (BOSI, 2013:15). La expropiación-explotación de los recursos naturales y el sometimiento de las comunidades indígenas y africanas por las potencias europeas marcó la historia latinoamericana. No sólo durante el sistema colonial, sino que, ha permeado las estructuras político, sociales e inclusive económicas de nuestra región hasta la actualidad a través de la colonialidad; la cara oculta de la modernidad (MIGNOLO, 2001:41).

Aníbal Quijano, por su parte, sostiene que la raza, a partir del período de colonización de América, se constituye como la nueva clasificación social de la población mundial en la Era Moderna. A través de esta forma de dominación, mediante la utilización del concepto de "raza", los europeos se autoestablecen como superiores y como el nivel más avanzado de civilización, a partir de una concepción eurocentrica de mundo.

\begin{abstract}
Um dos eixos fundamentais desse padrão de poder [colonial] é a classificação social da população mundial de acordo com a idéia de raça, uma construção mental que expressa a experiência básica da dominação colonial e que desde então permeia as dimensões mais importantes do poder mundial, incluindo sua racionalidade específica, o eurocentrismo. Esse eixo tem, portanto, origem e caráter colonial, mas provou ser mais duradouro e estável que o colonialismo em cuja matriz foi estabelecido. Implica, conseqüentemente, num elemento de colonialidade no padrão de poder hoje hegemônico. (QUIJANO, 2005:117)
\end{abstract}

Ese padrón de poder establecido fue concomitante al surgimiento de la economia-mundo moderna, y sirvió como base estructural tanto de la dominación colonial como para el surgimiento y desarrollo de la economia capitalista mundial. Las potencias europeas coloniales, al crear la colonialidad de poder, establecen su poder sobre el "control del trabajo, como de sus recursos y de sus productos, en torno del capital y del mercado mundial" (2005:227). La colonialidad en su totalidad, y el racismo en particular, se constituyen así como uno de los pilares estructurantes del sistema mundial moderno capitalista.

Esa colonialidad permea las sociedades, estructuras y realidades latinoamericanas. Varios autores identifican por lo menos cuatro o cinco ejes de esa colonialidad. Catherine Walsh, por ejemplo, sintetiza cuatro ejes en los que para ella y otros autores, como Quijano, la colonialidad ejerce su potestad. El primero sería el de la colonialidad del poder - explicada brevemente en la citación - que se refiere al establecimiento de un sistema de clasificación social basada en una jerárquica racial y sexual, dónde los hombres, blancos, heterosexuales, cristianos y occidentales se posicionaban en el alto topo de la "escala" de superioridad. El 
segundo eje es la colonialidad del saber, entendida, de manera simple, como el posicionamiento del eurocentrismo como la perspectiva única del conocimiento, colocando la racionalidad europea, masculina y blanca como la única posible. La colonialidad del ser, que sería el tercer eje, es la que se ejerce, para Walsh, "por medio de la inferiorización, subalternizacion y la deshumanización: a lo que Frantz Fanon (1999) se refiere como el trato de la «no existencia»." (WALSH, 2008:138).

El cuarto eje es el de la colonialidad de la madre naturaleza y de la vida misma, encontrando "su base en la división binaria naturaleza/sociedad, descartando lo mágicoespiritual-social, la relación milenaria entre mundos biofísicos, humanos y espirituales, incluyendo el de los ancestros, la que da sustento a los sistemas integrales de vida y a la humanidad misma" (Idem). Otro eje de la colonialidad que reconocemos es la colonialidad de género, basada en la instauración de una lógica patriarcal de género, en el que el hombre se establece como superior y la mujer como inferior (SAFFIOTTI, 2015). Esa lógica de dominación, jerarquía y explotación es fruto también, en gran medida, de la colonización.

Otro autor latinoamericano crítico de la Modernidad y del proceso de colonialidad es Enrique Dussel. Este autor en su libro 1492: el encubrimiento del otro: hacia el origen del mito de la modernidad (1994), realiza una crítica a la Modernidad tanto como concepto como discurso emancipador racional. Para él, al confrontarse esa modernidad - nacida en 1492 con las experiencias de los/as oprimidos/as se desvela como la más irracional de las violencias, configurándose así como un mito como justificación de esas violencias. Dentro de los varios análisis presentes en la obra resaltamos la propuesta de que esa Modernidad eurocéntrica fue basada en el encubrimiento del "Otro" no europeo, o sea, del negro, indígena, mujer, como contra-cara del "descubrimiento". A su vez, propone que una vez reconocidos y conquistados los territorios geográficos se pasaba al control de los cuerpos de las personas, por que era necesario "pacificarlos" y para ello, el "Conquistador", hombre moderno y activo, imponía su "individualidad" violenta al "Otro" (1994:40).

El conquistador mata al varón indio violentamente o lo reduce a la servidumbre, y
"se acuesta" con la india (aun en presencia del varón indio), se "amanceba" con ellas
se decía en el siglo XVI. (...) Se trata del cumplimiento de una voluptuosidad
frecuentemente sádica, donde la relación erótica es igualmente de dominio del Otro
(de la india). Sexualidad puramente masculina, opresora, alienante, injusta. Se
"coloniza" la sexualidad india, se vulnera la erótica hispánica, se instaura la doble
moral del machismo: dominación sexual de la india y respeto puramente aparente de
la mujer europea. De allí nace el hijo bastardo (el "mestizo", el latinoamericano,
fruto del conquistador y la india) y el criollo (el blanco nacido en el mundo colonial
de Indias) [p.51] (...) La "colonización" o el dominio del cuerpo de la mujer india es
parte de una cultura que se basa también sobre el dominio del cuerpo del varón 
indio. A éste se lo explotará principalmente por el trabajo (una nueva económica). En el tiempo de la acumulación originaria del capitalismo mercantil, la corporalidad india será inmolada y transformada primeramente en oro y plata -valor muerto de la objetivación del "trabajo vivo" (diría Marx) del indio- [p.52] (...) El "yo colonizo" al Otro, a la mujer, al varón vencido, en una erótica alienante, en una económica capitalista mercantil, sigue el rumbo del "yo conquisto" hacia el "ego cogito" moderno. La "civilización", la "modernización" inicia su curso ambiguo: racionalidad contra las explicaciones míticas "primitivas", pero mito al final que encubre la violencia sacrificadora del Otro. La expresión de Descartes del ego cogito, en 1636 será el resultado ontológico del proceso que estamos describiendo: el ego, origen absoluto de un discurso solipsista. [p.53] (DUSSEL, 1994)

Ese hombre "Conquistador" era además un ego violento y guerrero naciente, un "ego fálico" que realizaría la violencia erótica para mostrar y efectivizar la "colonización" del mundo de la vida indígena (1994:50). Ahora los hijos no serían sólo indígenas, serían frutos de la violencia colonizadora, serían bastardos, y las mujeres llevarían en sus cuerpos la marca, la escritura de la histórica violación (SEGATO, 2013), de la colonización de sus cuerpos, de sus sexualidades, de sus hijos, de su vida y mundo.

Bosi, de la mano de Marx, nos ayuda a comprender como esa acumulación originaria, vinculada también a la corporalidad tanto de la mujer como del hombre indígena, fueron parte del marco inaugural del surgimiento y desarrollo del capitalismo. Éste, a su vez, a través del proceso de colonizador, con su "efecto modernizante", contradictoriamente, es capaz de accionar o reinventar regimenes arcaicos de trabajo (y no el asalariado como em Europa), comenzando por el exterminio o la esclavitud de los nativos em las áreas de mayor interés económico (BOSI, 2013:20)

Con esto queremos resaltar no sólo el papel relevante de América Latina en la conformación del Sistema Mundo Moderno y de la economía capitalista mundial, sino que la constitución de esos procesos fueron posibles a través de la violencia impuesta por el "colonizador" a los pueblos que aquí vivian antes de su llegada. Asi mismo, América Latina fue constituida no sólo como la periferia de la economia-mundo sino también fuimos la primera "periferia" de la Europa moderna (DUSSEL, 1994:11), ya que el "ego" europeo - expresado primeramente por Descartes -, se constituiría como uno de los pilares fundamentales en el proceso de constitución de la "subjetividad" moderna, que forjará como estructura principal el eurocentrismo. Este, tal como Walsh y Quijano establecen, es uno de los aspectos fundantes de los diversos ejes de la colonialidad.

\section{ESTADOS NACIONALES, DIVISIÓN INTERNACIONAL DEL TRABAJO Y EL PROBLEMA DEL “OTRO”}


La colonialidad, como ya dijimos, es una marca aún presente en América Latina. La historia de nuestro continente nos muestra como luego de las independencias de las metropólis coloniales europeas, si bien la región pasó por importantes transformaciones, no se pudo superar esa otra cara de la modernidad. Los estados nacionales surgidos durante el siglo XIX en Latinoamérica, además de conformarse desde una visión eurocéntrica y aún colonial, también continuaron con las prácticas violentas hacia las poblaciones subalternas, tales como indígenas y negros. Pero ahora, con un nuevo papel en economía mundial, a través de su inserción en la división internacional del trabajo.

Bosi nos recuerda el caso de las llamadas "Conquistas del desierto" ocurridas en Argentina durante la segunda mitad del siglo XIX por orden del gobierno nacional y fueron verdaderos genocidios indígenas (principalmente del pueblo Mapuche). Esas campañas de "conquista" al llamar a esas tierras de "desierto", negaban e en-cubrian al "Otro", utilizando la expresión de Dussel, al no reconocer la existencia de poblaciones en la extensión del territorio que hoy comprende ese país. Las mismas tuvieron como principales objetivos extender y delimitar las fronteras nacionales, así como apoderarse de grandes extensiones de tierra que pudieran servir para producción y pastoreo de ganado, ya que la industria frigorífica aumentaba y precisaban saciar la demanda, proveniente fundamentalmente de Inglaterra. (BOSI, 2013:21).

Por que essa ambição de terra? Certamente, para centruplicar o gado vacum, porque
se havia centuplicado o seu valor no mercado inglês. Pois já não se contavam só o
couro, o sebo, os chifres e os cascos. Também a carne passou a ser um grande
negócio, no exterior, desde que o francês Thillier descubriu a sua conservação pelo
frio e surgiram as companhias exportadoras como The River Plate Fresch Co. ou La
Negra. Chama a atenção e dá o que pensar a circunstância de que a época da
conquista del desierto coincida com a abertura do mercado internacional de carne e
com a grande invenção do frigorico (1876). Um passo progressista do capitalismo,
sem dúvida. (GALICH Apud BOSI:21)

Ese tipo de campañas no sólo ocurrieron en Argentina, sino también en Chile con las “Campañas del Araucaria”, en Uruguay con las Masacres de Mataojo y Salsi Puedes (en la década de 1830) y la expansión brasileña hacia el oeste, además de las conocidas campañas de los Bandeirantes iniciadas durante el siglo XVI, que fue desarrollada fundamentalmente en la década de 1880. Ésta última, por ejemplo, además de ser una expansión militar con el objetivo de delimitar las fronteras y proteger el territorio nacional, buscaba garantizar la ocupación de 
tierras para extracción y producción de madera y yerba mate en el momento de auge de estos productos en el mercado internacional ${ }^{4}$.

Además de tener motivos económicos y territoriales, estos procesos - sobre todo los primeros tres- se proponían resolver las "cuestiones indígenas" que enfrentaban sus países. Luego de las independencias, muchos caciques indígenas que habían colaborado con la liberación del poderío colonial, se mostraron "descontentos" y no aceptaban el papel otorgado por las élites criollas en los nuevos estados nacionales (COELHO PRADO, 2008:600-601). Reformas agrarias que no contemplaban a sus comunidades, en las que se les retiraba y negaba el derecho de posesión sobre sus territorios ancestrales, negación de su participación en las luchas por la independencia, y un no-lugar en los propios estados nacionales, fundamentalmente, en los espacios de poder político, eran algunos de los motivos de ese "descontento". El progreso económico buscado por las élites criollas gobernantes necesitaba de tierras para producir, al mismo tiempo, era necesario eliminar los rastros de la barbarie representada por las comunidades indígenas. Las respuestas de los estados nacionales fue, correspondiendo a las prácticas del pasado colonial reciente, de masacre, exterminio, saqueo. Así se fundan y consolidan los estados nacionales de nuestra región.

Más adelante retomaremos el análisis del lugar dado a los sectores subalternos indígenas, negros, mujeres, pobres, no propietarios - en la consolidación de los estados nacionales. Pero ahora nos centraremos en examinar más detenidamente el proceso de inserción de América Latina en la división internacional de trabajo. Que, como pudimos ver anteriormente - sobre todo en el caso argentino -, jugó un papel determinante en los discursos y acciones de las élites latinoamericanas durante la solidificación de los Estados en nuestra región.

Si bien nuestro continente estuvo, desde la invasión y colonización de América, inserido en el incipiente Sistema Mundo Moderno, y tuvo un papel destacado en el surgimiento y desarrollo de la economía-mundo que daría vida al capitalismo, es solamente en el siglo XIX - más precisamente desde 1840 - que se estructura y articula plenamente con la economía mundial (MARINI, 2011:135).

Isto se explica se considerarmos que é com o surgimento da grande indústria que se establece com bases sólidas a divisão internacional do trabalho. A criação da grande

4 Informaciones obtenidas a través de la realización del Curso de extensión Breve historia de la Triple Frontera en 2013. El curso fue ofrecido por la Universidade das Américas - UNIAMÉRICA, de Foz de Iguazú, y ministrado por el prof. de Historia, Micael Silva. 
indústria moderna seria fortemente obstaculizada se não houvesse contado com os países dependentes e tido que se realizar sobre uma base estritamente nacional. De fato, o desenvolvimento industrial supõe uma grande disponibilidade de produtos agrícolas, que permita a especialização da sociedade na atividade especificamente industrial. (MARINI, 2011:135-136)

A su vez, explica Marini, la función cumplida por América Latina en la conformación de la división internacional del trabajo, no fue únicamente la producción de productos de subsistencia de origen agropecuario - que posibilitó la especialización de los países industriales como productores mundiales de manufacturas- sino también fue su contribución para la formación de un mercado de materias primas industriales, cuya importancia crece en función del mismo desarrollo industrial (MARINI, 2011:137). Además contribuir para que "el eje de acumulación en la economía industrial pase de la producción de plus-valia absoluta para la de plus-valia relativa" (Idem, 2011:138). Es a partir de estos procesos que se conforma lo que el autor llama de capitalismo sui generis, que tiene ciertas especificidades propias de nuestra región ${ }^{5}$ : dentro de la división internacional del trabajo tiene una relación de subordinación de las naciones formalmente independientes con los países centrales.

Como demostrado, estos fenómenos fueron favorecidos fuertemente por el surgimiento de los estados nacionales latinoamericanos. La existencia de los mismos contribuyó, tanto por fornecer productos primarios para la industria europea como por ser un mercado abierto a las manufacturas y capitales ingleses, para el proceso de acumulación de capital y el desarrollo de una nueva fase de la economía capitalista mundial fundamentalmente a fines del siglo XIX (SOUZA, 2009:14), desencadenada por los propios avances de la dicha economía. Esta fase será llamada de imperialismo.

\begin{abstract}
No periodo imperialista, os emprestimos externos desempenham papel extraordinário como meio de emancipação dos novos Estados capitalistas. O que existe de contraditório na fase imperialista se revela claramente nas oposições características do moderno sistema de empréstimos externos. Eles são impresindiveis para a emancipação das nações capitalistas o meio mais seguro de tutelar os novos Estados, de exercer controle sobre suas finanças e pressão sobre sua política externa, alfandegária e comercial. Os empréstimos são um meio extraordinário para abrir novas áreas de investimento para o capital acumulado dos paises antigos e para criar-lhes, ao mesmo tempo, novos concorrentes; são o meio de ampliar, no geral, o raio de ação do capital e de reduzi-lo concomitantemente. [...] A exportação de capital inglés para a América desempenhou papel de enorme importância já no inicio dos anos 20 do século passado [haciendo referencia al siglo XIX] (LUXEMBURG, 1984:66-67).
\end{abstract}

Otro factor fundamental fue el de los prestamos de capital inglés a los países nacientes latinoamericanos tanto para el desarrollo de una tímida industria nacional como de la

5 Esas especificidades, según Marini, básicamente son: la super-explotación de la fuerza de trabajo, la transferencia de valor y la cisión del Ciclo del Capital (Ver Marini, Dialéctica de la dependencia (2011)). 
construcción de infraestructura que posibilitase el comercio y la propia compra de mercancías, ya que los estados emergentes no poseían grandes capitales propios. Esto, principalmente, por dos motivos. El primero, porque el excedente acumulado en los tiempos coloniales se dirigía al exterior (a las metrópolis, por ejemplo). Segundo, porque luego de las guerras de independencia las economías locales se vieron envueltas en una gran crisis (COELHO PRADO, 2004:69). En ese sentido,

Entre 1824 e 1825, as nações recém-constituidas da América Central e do Sul haviam tomado, em empréstimos públicos, mais de 20 milhões de libras esterlinas de Londres. Além disso chegaram a Londres enormes quantidades de ações industriais sul-americanas. Por outro lado, a súbita expansão e a abertura dos mercados sul-americanos haviam ocasionado forte elevação das exportações de mercadorias inglesas para os países sul e centro-americanos. A exportação de mercadorias britânicas para esses países chegavam a 2,9 milhões de libras esterlinas em 1821 e em 1825 já era de 6,4 milhões. O principal objeto dessas exportações eram tecidos de algodão. Sob o estímulo dessa demanda intensificada, a produção algodoeira inglesa ampliou-se rapidamente, fundando-se inúmeras novas fábricas. (LUXEMBURG, 1984:67).

Con esto podemos observar que América Latina, en los primeros años de su independencia, tuvo un papel destacado en el desarrollo acelerado de la industria inglesa. Resaltando que en esos momentos la potencia hegemónica era Inglaterra, quién encabezaba el tercer ciclo sistémico de acumulación capitalista desde, por lo menos, más de un siglo (ARRIGHI, 2012:51). Consolidada y en expansión potencial, la industria inglesa precisaba de nuevas fuentes de materias primas como de nuevos mercados para introducir sus productos manufactureros, por lo que comenzaron a pregar el libre-comercio, que fue apoyado fuertemente por las oligarquias agrárias latinoamericanas (SOUZA,2009:3). La independencia política de las colonias americanas brindaba la posibilidad de Inglaterra conseguir satisfacer, en nuestro continentes, ambas necesidades. Ahora, sin la intervención y el proteccionismo de los imperios portugués y español frente al poderío inglés.

La productividad industrial inglesa estaba pasando desde hacia décadas por un proceso de crecimiento y aceleración, producto de la Revolución Industrial, y la expansión material del capital dieron como resultado la globalización de la economía mundial capitalista (ARRIGHI, 2012:165), en la que nuestra región tuvo un papel importante. Esa globalización tendría como característica principal la división internacional del trabajo, en la que Europa productora y exportadora industrial se (re)configuraría como el centro y América Latina, especializada en la producción y exportación de productos primarios (SOUZA, 2009:6), se ubicaría en la periferia de la economía mundial capitalista y, nuevamente, en la periferia del 
Sistema Mundo Moderno. Así se establecen las estructuras del capitalismo dependiente latinoamericano, característica aún actual de nuestros países.

Comprendiendo entonces el relevante papel de los estados nacionales latinoamericanos emergentes en la configuración de la economía mundial del siglo XIX, a través de la división internacional del trabajo, nos enfocaremos ahora en otros aspectos de la consolidación de los mismos. Brindaremos mayor atención al lugar que los sectores subalternos ocuparon en esas nuevas naciones que surgían y en cómo las élites dominantes crearon diversas formas de dominación y control sobre esas poblaciones.

Ya explicamos como las masacres, el exterminio y el saqueo, principalmente de las comunidades indígenas, caracterizó no sólo el proceso de colonización sino de la propia consolidación de los estados nacionales en la región. Ambos procesos fueron "justificados" por una Modernidad eurocéntrica, violenta, creadora y encubridora del "Otro".

Por su lado, las influencias francesas y británicas contribuyeron para que los ideales liberales modernos fueran fuertemente apropiados y difundidos por los defensores de la independencia de las colonias americanas. Entre ellas se destacaba la creencia de la razón uno de los elementos fundamentales de la Modernidad - como guía de las acciones humanas, en la centralidad del individuo en el recorrido de la historia, en la defensa de los derechos naturales de los hombres tales como la libertad, la igualdad jurídica y la legitimidad de la propiedad privada (COELHO PRADO, 2004:53). Al consagrarse la liberación del poderío colonial, las élites dominantes buscaban construir nuevos estados en medio de inmensas disputas entre sus más diversos sectores y frente al desespero, cada vez mayor, de los humildes, ya que su vida continuaba dominada por la pobreza y la opresión, y era tratada con desinterés y falta de respeto (Idem, 2004:73)

En ese sentido, la historiadora Maria Ligia Prado nos ayuda a comprender como indígenas, negros, mujeres, entre otros, fueron relegados al lugar se subalternos, o mejor, les fue dado un no-lugar en las naciones incipientes.

La nación, en sus distintas formas, se adentró en la producción historiográfica, períodistica, ficcional y artística. Pero, ¿quién componía la nación? Según la voz oficial de las élites, la nación surgía encuadrada por la armonía, como el lugar de los blancos racionales y letrados que tenían derecho legítimo, basado en sus capacidades y en su trabajo, de poseer propiedades y dirigir el Gobierno. Los negros, los indios, los mestizos, los pobres, las mujeres, los no propietarios, los campesinos, todos incapaces (según las élites) de comprender la res publica, eran simples coadyuvantes que deberían tener un papel subordinado y controlado en la sociedad. La dicotomía 
civilización - barbarie justificaba el dominio de los primeros sobre los segundos. (COELHO PRADO, 2008:600)

Según la autora, para las élites gobernantes el "pueblo" no estaba preparado para los cambios, por lo que, mientras se preparaba, la respuesta del nuevo estado debía ser un estricto control social basado en la represión policial y en el orden autoritario. Así mismo,

\begin{abstract}
Aqueles que dispunham de poder e traduziam os interesses econômicos dominantes tinham, diante de si, um rol de tarefas complexas. Era necessário construir novos Estados, com instituições que garantissem a ordem e o controle sociais, mas que também conferissem legitimidade aos que governam [...] Porém, para aqueles que não dispunham de recursos, quer econômicos, quer culturais, os novos tempos não trouxeram benesses ou regalias. Reformas sociais de peso, terra, salários dignos, participação política, educação popular, cidadania, respeito cultural às diferenças, tudo isso teria de esperar. As ações de governos autoritários cobriram e deixaram suas marcas registradas na América Latina durante a maior parte do século XIX. Os de "baixo" teriam de se organiza, lutar, sofrer e morrer para alcançar seus objetivos. Não foram as lutas de indepêndencia que mudaram sua vida (COELHO PRADO, 2004:73).
\end{abstract}

Al mismo tiempo que América Latina se insertaba en la división internacional del trabajo y las élites nacionales colaboraban para la estructuración de un capitalismo dependiente, internamente construían la nación, las instituciones necesarias para el funcionamiento de los nuevos estados y de la economía, tanto del campo agro-exportador como de la industria incipiente. Concomitantemente, a través de las invenciones de las identidades nacionales ${ }^{6}$, definían el lugar para cada uno de los sectores de la población dentro de esa nación. La razón y la violencia, ambas propias de la Modernidad, se conjugaban fuertemente con las ideas de progreso, civilización y orden. Estos elementos marcaron los procesos de consolidación, construcción e invención de los estados nacionales latinoamericanos.

Desde la independencia, las élites latinoamericanas aspiraban a consolidar su
dominación sobre la sociedad, basada en una identidad homogénea que les
garantizase la hegemonía política. De este modo, se postularon como poseedoras del
<<espíritu civilizador blanco >> y de la <<razón letrada〉>, lo cuál les confería
legitimidad para situarse por sobre los negros, los indios y los mestizos, y así
justificar su poder. La repetición de las imágenes, los símbolos y los valores en los
discursos dominantes pretendía construir una identidad nacional que les reservase
ese lugar de privilegio. La descalificación sistemática de los de abajo justificó su
exclusión de la esfera política y garantizó que las élites continuaran en el poder.
Éstas, no obstante, no lograrían jamás hacer desaparecer a ese <<otro〉>, negado y
mostrado como inferior o como bárbaro. (COELHO PRADO, 2008:584).

La transición de ser colonias europeas a estados independientes no significó para los sectores subalternos una ruptura directa con la pobreza y la opresión. Ahora, por el contrario, bajo el discurso de la igualdad y de la nación se buscaba solapar e invisibilizar a esos "Otros"

6 Al utilizar este término hacemos referencia a la concepción teórica brindada por Eric Hobsbawn y Ranger Terence en su libro A invenção das tradições (1997). 
a través del mito civilizador y de una supuesta identidad nacional. Como vimos con los análisis de Quijano, Walsh y Dussel, la colonialidad, como la cara "oculta” de la Modernidad, marcó la historia y realidades de las sociedades latinoamericanas.

La colonialidad del poder, del saber, del ser, de la naturaleza y del género fueron (re)configuradas con los Estados Nacionales pero no pudieron ser superadas. Las élites latinoamericanas, muchas hijas directas tanto histórica, biológica como intelectualmente de las metrópolis europeas, no estaban dispuestas a compartir las riquezas y el gobierno de la nación con los "Otros", con los pobres, indígenas, negros. El eurocentrismo, el racismo y el clasismo fueron componentes de las miradas, discursos y prácticas dirigidas por los gobernantes hacia los sectores populares latinoamericanos. Sólo el hombre, occidental, blanco, propietario y heterosexual tenía el derecho de gobernar, dominar y usufructuar de las ganancias producidas a cuestas de la sobre-explotación, término utilizado por Marini (2011), de "los de abajo".

\section{CONSIDERACIONES FINALES}

La invasión y colonización de América fue un acontecimiento crucial en esa "acumulación originaria" necesaria para el surgimiento y desarrollo tanto del Sistema Mundo Moderno como de la propia economía capitalista mundial. Estos procesos que contribuyeron para el establecimiento de las relaciones económicas y políticas jerarquizadas entre naciones y regiones, dónde Europa se construyo como el centro y América Latina como la periferia, fueron realizados a través de la violencia, del exterminio, el saqueo, la esclavitud, y posteriormente, la super-explotación de nuestras clases populares oprimidas.

A su vez, durante el siglo XIX, con mayor fuerza en la segunda mitad, los estados nacionales emergentes estaban en proceso de consolidación. En la esfera exterior, o mejor, internacional, las naciones latinoamericanas, ya no a las colonias, estaban en proceso de inserción en la economía mundial. Al mismo tiempo, los estados incipientes necesitaban demostrar a las antiguas metrópolis que eran países con instituciones firmes, una sociedad ordenada, y una población dispuesta a trabajar para "colaborar" con el progreso de las naciones, y al conseguir un nivel de "civilización” adecuado.

Se delimitaron así las condiciones que deberían cumplir los habitantes para transformarse en ciudadanos civilizados, y con ello, se construyó un ideal normativo, simbólico y político de "buen" ciudadano y su opuesto, el "mal" ciudadano, que sería visto 
como "peligroso" para el orden y progreso de la nación que se conformaba. Ese "mal" fue asociado por las élites dominantes con el "Otro", aquél que pertenecía a la barbarie, que no podía gobernar, que era inferior, tanto económica, patriarcal como racialmente. negros, mujeres, indígenas, no-propietarios, trabajadores fueron inventados dentro de los estados nacionales como inferiores. Garantizando el lugar a las élites económico-políticas herederas de las ex-colonias el derecho a gobernar. Ellos se auto imputan la superioridad ilustrada.

Esta dinámica de "delineación” interna/externa contribuyó para la creación y difusión en América Latina de una mirada social, pero fundamentalmente institucional, que criminalizaría todo aquél sujeto que no se adecuara a las "necesidades" e imposiciones que requería el estado nacional. De esa forma, comprendemos cómo con las independencias no se superó la colonialidad, y a su vez, cómo esta sirvió - y sirve hasta hoy - para las élites dominantes mantener su poder, su jerarquía sobre las clases populares. Los momentos no son los mismos, hubo rupturas, eso es claro, pero las continuidades existen y negarlas sería un gran error. Reconocer es necesario para superar. Por ello, es a partir de este tipo de análisis que conseguimos comprender mejor el lugar de América Latina en la historia y economía mundial y cómo la violencia, saqueo y (super)explotación de nuestros pueblos fue y es la base para el crecimiento, desarrollo y expansión del capitalismo mundial.

\section{REFERENCIAS BIBLIOGRÁFICAS}

ANDERSON, Perry. Linhagens do Estado absolutista.Traducción João Roberto Martins Filho. São Paulo: Brasiliense, 2004.

ARAUJO SOUZA, Nilson. Economia Internacional Contemporânea. Ed. Atlas: São Paulo, SP, 2009.

ARRIGHI, Giovanni. O Longo Século XX. Sao Paulo: Ed. Unesp, 2012.

BOSI, Alfredo. Diáletica da colonização. São Paulo: Companhia das Letras, 2013.

CARVALHO, Wolney R.; FRIGGERI, Félix P. Desarrollo económico y/o buen vivir: Dilema actual del latinoamericano. En: Textos de Economia, Florianópolis, v.16, n.1, p.117-137, jan./jun.2013

DUSSEL, Enrique. 1492: el encubrimiento del otro. Hacia el origen del mito de la modernidad. La Paz: Plural, 1994. 
HOBSBAWM, Eric \& TERENCE, Ranger. A Invenção as tradições. Rio de Janeiro: Paz \& Terra, 1997.

LEDEZMA, Gerson. Colonialidad, eurocentrismo e nacionalismo na américa latina. In Carlos Domínguez; Lídia Xavier (orgs.). Política, Cultura e Sociedade na América Latina: Estudos Interdisciplinares e Comparativos (v. 2), Curitiba: Editora CRV, 2015.

LUXEMBURG, Rosa. 'Os empréstimos internacionais'. Em: A acumulação do capital. São Paulo: Abril Cultural, 1984, Vol. 2, ps. 65-82.

MARINI, RUY MAURO. A Dialética da dependencia. En: Ruy Mauro Marini - Vida e obra (textos selecionados). Sao Paulo: Expressao Popular, 2011.

MARX, K. O Capital. Livro 1 volume 1 e 2. México: Fondo de Cultura Ecońomica, 1988.

MIGNOLO, Walter. "La colonialidad: la cara oculta de la modernidad". Edición en castellano, Cosmópolis: el trasfondo de la Modernidad. Barcelona: Península, 2001

PERROT, Michelle. OS EXCLUIDOS DA HISTORIA: OPERÁRIOS, MULHERES, PRISIONEIROS. Rio de Janeiro: Editora Paz e Terra, 1988.

PORTAL TeleSur Tv. [noticia]. Macri intenta atenuar crisis económica con nuevas medidas. Venezuela: Tele Sur, publicado 16 de abril del 2016. Disponible en: http://www.telesurtv.net/news/Macri-intenta-atenuar-crisis-economica-con-nuevas-medidas20160416-0027.html . Acceso: 26/06/2016.

[noticia] Gobierno de Macri lleva 154 mil 786 despidos en Argentina. Venezuela: Tele Sur, 18 de mayo del 2016. Disponible en: http://www.telesurtv.net/news/Gobiernode-Macri-lleva-154-mil-786-despidos-en-Argentina-20160518-0002.html . Acceso: 26/06/2016.

PORTAL UOL. [noticia] Michel Temer discursa apor assumir presidencia. Versión digital. Site: Uol. Publicado 21/05/2016. Disponible en: http://noticias.uol.com.br/politica/ultimasnoticias/2016/05/12/michel-temer-discursa-apos-assumir-presidencia.html . Acceso: 26/06/2016.

PRADO, Maria Lígia Coelho. América Latina no século XIX. Tramas, Telas e Textos. São Paulo: Edusp, 2004.

Identidades Latinoamericanas. En: Historia General de América Latina, vol VII. Los proyectos nacionales latinoamericanos: sus instrumentos y articulación, 1870-1930. Madrid: Unesco/Trotta, 2008, pp. 583-616. 
QUIJANO, Anibal. “Colonialidad del poder, eurocentrismo y América Latina”. Buenos Aires: Colección Sur Sur, CLACSO, 2005.

SAFFIOTI, Heleieth. GENERO, PATRIARCADO, VIOLENCIA. Sao Paulo: Expressao Popular, Fundacao Perseu Abramo, 2015.

SEGATO, Rita. Las estructuras elementales de la violencia. Ensayos sobre género entre la antropología, el psicoanálisis y los derechos humanos. 1a ed. Bernal: Universidad Nacional de Quilmes, 2003.

. La escritura en el cuerpo de las mujeres asesinadas en Ciudad Juárez Territorio, soberanía y crímenes de segundo estado. 1a. Ed. Buenos Aires: Tinta Limón, 2013.

TODOROV, Tzvetan. La conquista de América: el problema del otro. Madri, México: Siglo Ventiuno, 1998.

WALLERSTEIN, Immanuel. O sistema mundial moderno. Vol. I: A agricultura capitalista e as origens da economia-mundo europeia no século XVI. Porto: Edições Afrontamento, s.d. [1974].

WALSH, Catherine. Interculturalidad, pluralidad e decolonialidad: las insusurgencias políticoepistemicas de refundar o Estado. In: Tabula Rasa, vol. 9, 2008, pp. 131152.

RODRÍGUEZ M., HOLMAN. [noticia] A Macri no le cuadran las cifras en Argentina. Versión digital. Site del periódico El tiempo. Colombia: El tiempo, sección mundo latinoamérica, publicado 14 de mayo del 2016. Disponible en: http://www.eltiempo.com/mundo/latinoamerica/gobierno-de-mauricio-macri-en-crisiseconomica/16593104 . Acceso: 25/06/2016. 